\title{
Unidad y diversidad en la Psicología
}

\author{
Juan Mayor
}

\section{Introducción}

Dos problemas han aquejado y aquejan a la psicología desde sus origenes hasta hoy mismo en forma tal que se justifica el permanente lamento sobre la crisis de la psicología; recordemos que así se titulaba un famoso libro de Bühler publidado en 1927 y así se titulaba, cincuenta años después, el libro de Westland en 1978 (e insistiendo en ello, Kendler en 1081 hablaba de un ciencia en conflicto).

Uno de los problemas es el de su validez, tanto interna (fudamento epistemológico, contexto de justificación, base racional) como externa (capacidad de generación y aplicación, contexto de descubrimiento, eficacia social); de este problema, con ser importante y decisivo, no vamos a ocuparnos ahora, porque pretendemos plantear y, si es posible, dilucidar otro problema previo, que es el de la propia identidad de la psicología. Los criterios que habitualmente se utilizan para definir la psicología -históricos, sistemáticos o pragmáticos - han resultado insuficientes, porque la falta de un amplio consenso entre la comunidad científica obliga a inclinarse siempre por una opción personal. Esto, que es legítimo e inevitable en la literatura o en la filosofía, plantea dificultades casi insalvables cuando nos movemos en el ámbito de la ciencia. La raíz de este problema, a nuestro juicio, se encuentra en la incapacidad o dificultad que hasta ahora ha mostrado la psicología para articular su evidente diversidad con la necesaria unidad de criterios epistemológicos, teóricos, metodológicos y pragmáticos. A clarificar este problema vamos a dedicar estas reflexiones: en primer lugar, poniendo de relieve la diversidad de la psicología, tanto desde una perspectiva disciplinar, como teórica o paradigmática; en segundo lugar, aludiendo a los diversos intentos de unificación; y en tercer lugar, constatando la existencia de una tensión dinámica o dialéctica entre la unidad y la diversidad y proponiendo una fórmula epistemológica para resolver esa tensión dilemática.

\section{Radical diversidad de la psicología}

A) Ya la posición disciplinar de la psicología plantea el problema de su unidad o diversidad. Cabe cuando menos dudar de la unidad de una disciplina, si justificadamente se puede hablar de un psicología filosófica, de una psicología como ciencia natural o como ciencia social e, incluso, comi ciencia del espiritu. Pero cabe también resolver el problema por el expeditivo procedimiento de considerar que la psicología como ciencia natural es la única disciplina digna de tal nombre y que el resto no es 
psicología, sino filosofía o antropología o sociología o cualquier otra cosa. Algo así quiso decir Ebbinghaus cuando afirmó que la psicología es una ciencia con un largo pasado y una corta historia.

Pero tal actitud ha de enfrentarse con dos dificultades: dar cuenta de la profunda y amplia reflexión que ha existido sobre el objeto de la psicología al margen de la ciencia y explicar la presión epistemológica que esa reflexión ejerce todavía sobre la psicología científica, incluso la más reciente.

1.- Por el momento parece que hay que resignarse a aceptar la diversidad disciplinar de la psicología. Y por si fuera poco, ni siquiera scría fácil excluir del saber psicológico aquel que se construye en el lenguaje ordinario como fruto de la intuición o reflexión individual o como sedimentación de las experiencias de sucesivas generaciones o culturas enteras.

Dentro de este saber psicológico no metódico ocupa un destacado lugar la interpretación literaria y artística de la naturaleza humana. Los trágicos griegos, Shakespeare, Dostoyevsky, Leonardo Da Vinci, Goya, etc., etc., han acumulado un inmenso acervo de observaciones penetrantes, de análisis sorprendentes sobre la naturaleza y la conducta humana (ver Lersch, trad. 1958, p. 55).

En este capítulo habria que incluir los conocimientos sobre el hombre que se han ido elaborando a través de costumbres, mitos, religiones y concepciones del mundo. La mayor parte de ellos no están suficientemente organizados, aunque parcialmente han sido objeto de investigaciones sistemáticas (recordemos Psique de Rhode, La rama dorada de Frazer, Yoga, inmortalidad y libertad de Mircea Eliade, etc.).

2.- La psicología filosófica si que es ya una disciplina en sentido estricto, aunque es muy dudoso que en ella se encuentre la unidad de la psicología en razón de la multiplicidad de escuelas y sistemas filosóficos en que se inscribe y sobre todo por ser una disciplina filosófica y por tanto problemática respecto de su propio objeto.

En primer lugar, la psicología no se distingue de la matriz básica de los saberes filosóficos. El mismo Aristótcles, que estructuró tantas disciplinas, no acertó a independizar la psicología de la ética, de la metafísica, de la física, de las ciencias naturales.

La psicología se independiza como disciplina en los siglos XVII y XVIII. La psicología racional fue identificándose paulatinamente con psicología especulativa, metafisica o filosófica sin más. La psicología empírica, que era filosófica también, fue poco a poco distanciándose de la anterior y terminaría por convertirse en experimental.

Todavía a principios del siglo $\mathrm{XX}$, autores afectos al movimiento neoescolástico dividian la psicología en dos: racional, especulativa, teorética y filosófica, por un lado; empírica y experimental, por otro; véase Frobes (1923, trad. 1944) o Lindworsky (trad. 1946).

La nueva psicología, científica y Experimental, surge en oposición a la vieja psicología filosófica. Su triunfo arrollador no supone, sin embargo, la desaparición de ésta. Al margen de la pervivencia en medio neoescolásticos de la vieja psicología racional, más o menos remozada, Mercier (1923, trad. 1940, 4 tomos), Marc (1948, trad. 1965), dos son los conceptos básicos de la psicología filosófica actual que han alcanzado resonancia, a los que aludiremos brevemente a continuación.

- Uno de ellos es el que tiende a identificarla con antropología filosófica, concepto 
muy amplio y diversificado a su vez, según las distintas orientaciones de base; véase Donceel (trad. 1969), Cassirer (1944), Martin Buber (1948), Beck (trad. 1947), Pinillos (1962), etc. Lo que es bien diferente de la existencia de modelos antropológicos en cada una de las orientaciones de la psicología cientifica (Pinillos, 198). Aquí habría que situar el movimiento que ha promovido el desarrollo de la psicología fenomenológica: a partir de Husserl, Scheler, Merleau-Ponty, Giorgi et al. (1975), Strauss (1966), Keen (1975), movimiento que ha historiado Spiegelber (1972) y que ha resumido y comentado Pinillos (1970), y al que habría que sumarle el de la psicologia existencialista, que arranca de movimientos filosóficos diferentes, aunque conexos por la aceptación general del método fenómenológico, y que ha evolucionado preocupada por llenar el hueco que deja la psicología científica a la hora de estudiar los fenómenos específicamente humanos: May (1961), Van Kaam (1969).

Todos estos movimientos actuales están en relación o tienden a agruparse, sobre todo en los Estados Unidos, bajo el denominador común de psicología humanística: Maslow (1965) Severin, (1966), Bugental (1967), Giorgi (1970), Barker (1971-2) Nevill (1977), Krasner (1978) y Royce y Mos (1981).

- Pero hay otra orientación que también reclama la etiqueta de psicología filosófica y que a nuestro juicio tiene una enorme importancia. Nos referimos a lo que se ha dado en llamar filosofía de la psicología (Misiak, trad., 1964, 146) y que forma parte del amplio movimiento de la filosofía de la ciencia o de la epistemología científica. Recordemos el ingente trabajo de aquellos que, inspirándose en el empirismo radical, trataron de establecer las bases teóricas de una psicología objetiva (conductista), de los que formularon sus críticas a la posición heredada y los que se enzarzaron en el espinoso problema de las relaciones mente-cuerpo.

Buena parte de estas grandes polémicas se encuentran en los sucesivos tomos de los Minnesota Studies in the Philosophy of Science y una selección de trabajos en esta línea puede verse en las distintas ediciones renovadas de Psychological Theory (1951) y Theories in Contemporary Psychology (1963 y 1976) de Marx (el último con Goodson). A los Feigl y Scriven (1956), Meehl (1954), Brunswik (1952) y Turner (1967), hay que sumar, por un lado, los Kuhn (1962), Feyeraben (1970), Toulmin (1972), Suppe (1977), y los Stevens (1935 y 1939), Ryle (1949), Fodor (1968, que subtitula su libro An Introduction to the Philosophy of Psychology), por otro; una revisión de problemas relativos a psicología y filosofía puede verse en Tumer (1967), Brown (1974), Eacker (1975) y más recientemente aún, en Bolton (1979) y Block (1980 y 1981).

La distinción entre psicología filosófica y psicología científica es bien patente: incluso, en muchas ocasiones tienden a ser opuestas, aunque existen numerosas interrelaciones entre ellas.

3.- Pero no se agota aquí la diversidad disciplinar de laz psicología. Parecería que solamente debería haber una psicología científica, pero históricamente no ha sido así. En el momento (finales del siglo XIX) en que se constituye la psicología como ciencia se plantea el problema de la clase de ciencia que puede estudiar adecuadamente la realidad humana, (Dilthey, 1894; Brentano, 1874; Husserl, 1910-11) y los ecos de esa disputa todavía resuenan en muchas de las discusiones actuales (Pinillos, 1981).

La poderosa corriente positivista va a tratar de imponer el modelo de la Naturwis- 
senschaft; pero las primeras dificultades metodológicas promovieron la aparición de una alternativa que trataba de estudiar al hombre como algo irreductible a naturaleza. Para ello se proponía un nuevo método y en consecuencia, una ciencia distinta. Frente a las ciencias nomotéticas, las idiográficas (Windelband); frente a la ciencia natural, la cultural (Rickert); frente a las ciencias positivas, las del espiritu (Dilthey). La psicología debería ser comprensiva y descriptiva y no analítica ni explicativa. Pero los desamollos de esta psicología no pudieron competir con los de la psicología como ciencia natural y positiva.

Sin embargo, su problemática ha tenido una gran influencia en la Gestalt, en la personalística de Stern, Spranger y Allport, así como en algunas características metodológicas de la psicología clínica (L'Abate, trad. 1967) y por supuesto, en la actual psicología humanística.

B) Si aceptamos los criterios de eficacia histórica, teórica y pragmática, hemos de convenir en que la psicología predominante a lo largo del siglo XX es la científicopositiva. Podríamos, pues, buscar en clla la unidad, considerando a las disciplinas antes citadas como meramente marginales y en decadencia. Pero las cosas no son tan sencillas: tampoco hay unidad en la psicología científico-natural.

1.- En efecto, el signo babélico de la psicología científico-positiva se manifiesta desde sus mismos comienzos. La fecha convencional de su nacimiento es la de 1879. En los años 70 se inicia la configuaración de la nueva ciencia. Junto al estructuralismo de Wundt y Titchener se desarrolla el funcionalismo de James y Dewey, el asociacionismo de Thorndike y el psicoanálisis de Freud. En los años diez de siglo XX surgen con fuerza dos escuelas rivales: el conductismo de Watson y la Gestalt de Wertheimer, Köhler y Koffka. Todos parecen enfrentarse a los supuestos básicos de Wundt, como han señalado numerosos autores (Wolman, Tomae y Feger, Yela, Pinillos): contra el atomismo asociacionista y elementalista, surge la Gestalt de orientación totalista; contra el énfasis sobre la conciencia, el psicoanálisis se centra en el inconsciente; contra el introspeccionismo y mentalismo, el conductismo y la reflexología imponen el objetivismo del esquema E-R; frente a las estructuras y a los estados de conciencia, el funcionalismo insiste en los procesos y en la adaptación al ambiente.

La disputa entre las escuelas parece surstituir al progreso acumulativo de la ciencia y Murchison se siente obligado a describir la situación de la psicología refiriéndose a las "psicologías" de 1925 (siete) y más tarde de 1930 (once), Heidbreder habla de siete "psicologías" (1933) y Woodworth de "psicologías" contemporáneas (1931). Y más todavía. En la revisión que en el Murchison del año 1930 hace Carr del funcionalismo escribe: "no hay una psicología funcional; más bien hay muchas psicologías funcionales". Una etapa importante, que ha dejado sus huellas hasta hace poco, es precisamente la de estos intentos de construir grandes sistemas de psicologia (McGeogh, 1933; Estes, 1954). No hay historia general de la psicología que no tome en cuenta estas escuelas : Wolman, Murphy, Boring, Klein, Schultz, Sahakian y algunos intentos de sistematizar la psicología actual, como los de Chaplin y Krawiec (1968) y de Marx y Hillix (1963), se basan en ellas (aunque luego las complementen con otras referencias a la actualidad).

Puede ser útil revisar la definición que de la psicología ofrecen los seis sistemas 
principales para constatar su diversidad: para el estructuralismo (Titchener), es "el estudio analítico de la mente humana adulta, normal generalizada, que se lleva a cabo mediante la instrospección". (Marx y Hillix, 1963, trad. 1967, p. 92); para el asociacionismo (Thorndike), es "el estudio de las conexiones o vínculos estímulosrespuesta" que "pueden estar en gran parte determinadas por hechos que precedieron a sus estímulos inmediatos o por una parte mayor o menor de la actitud concomitante o incluso por la constitución total del sujeto" (ibid, p. 135, 136); para el conductismo (Watson), "es la parte de la ciencia natural cuyo objeto de estudio es la conducta humana: las acciones y verbalizaciones, tanto aprendidas como no aprendidas de las personas" (ibid, p. 159); para los gestaltistas, es "el estudio de la experiencia inmediata del organismo total", con mayor "atención a las relaciones entre los antecedentes y la percepción que a las relaciones entre la percepción y la conducta" (ibid, p. 212); para el psicoanálisis (Freud), éste viene a ser, en interpretación de Marx y Hillix, "una disciplina que se inició en el estudio de las neurosis por medio de las técnicas hipnóticas, el análisis de los sueños y la asociación libre y destacó la importancia de las condiciones motivacionales inconscientes" (ibid. p. 244). La diversidad de la psicología es, pues, bien clara.

Es cierto que, a partir de los años trcinta, las escuelas perdieron actualidad y se sustituyeron por un neoconductismo generalizado, pero no es menos cierto que han mantenido hasta nuestros días una cierta vigencia como puntos de referencia, no solo históricos, sino teóricos. Esto puede verse en los trabajos del simposium de la A. P. A. (1967) recogidos en Krantz (1969) y en dos artículos de Fuchs y Kawash (1974) sobre los rasgos de las escuelas y la estructura de sus interacciones. Los datos para este último análisis fueron proporcionados por 68 psicólogos americanos $y$, como base opcracional para describir las escuelas, se utilizaron las 36 dimensiones prescriptivas de Watson (1967) a las que se asignó una escala de 7 puntos. En la Tabla 1 recogemos las medias de puntuación para cada escuela y cada dimensión. Sobre estas puntuaciones se realizó un análisis factorial que descubrió la existencia de 7 factores cuyas corrclaciones superiores a 50 con las diferentes dimensiones se recogen en la Tabla 2 elaborada por nosotros con los datos de Fuchs y Kawash. Las puntuaciones correspondientes a estos 7 factores para cada una de las 5 escuelas se recogen en la Tabla 3 .

Estos factores, como puede verse, ayudan a poner de manifiesto la interpretación de los datos y las descripciones teóricas de las distintas escuelas, así como sus desacuerdos y concordancias subyacentes. En cualquier caso, y en apoyo de nuestra argumentación, la diversidad de la psicología, desde la perspectiva de las escuelas, aparece con acusados perfiles.

A todo ello habría que añadir la consideración de escuelas que muchos otorgan a ciertos autores - y sus seguidores - o a ciertas corrientes contemporáneas no vinculadas directamente a las citadas. Por ejemplo, para algunos, el neoconductismo es una escuela diferente del conductismo; para Krantz, el Skinnerianismo es una escuela independiente, a juzgar por la bibliografía; dentro de la orientación cognitiva, entre otras muchas (Mayor, 1980), se habla insistentemente de la escuela de Piaget o escuela de Ginebra; el número de escuelas psicoanalíticas es incontable (Wyss, 1961); es frecuente más reducidos, el término escuela de suele utilizar también con profusión: la escuela de Dilthey, la del Acto, la de Würzburg, la de Iowa (Spence, Taylor), etc, etc... 
Véase las historias de Murchison (1925, 1930), Heidbreder (1933, traducción española, 1960), Krantz (1969), Sahakian (1975), etc.

2.- La psicología también se diferencia por los distintos esquemas, orientaciones, enfoques o paradigmas que utiliza, asi como por las teorías que desarrolla o los tipos de leyes que trata de establecer o por los rasgos o dimensiones que caracterizan o definen a sus variadas teorías, metateorías y metodologías.

Es frecuente considerar la distinción entre tres tipos de psicología según que sus objetos sean el alma, la mente o la conducta.

Brunswick (1952, p. 51) considera la existencia de seis esquemas principales en el desarrollo de la psicología, tres de ellos introspeccionistas: filosofía especulativa, sensacionismo e intencionalismo; y tres enfoques objetivos: micro-fisiologismo, conductismo clásico y psicología objetiva funcional.

Fraisse (1968-9) propone cinco modelos: psicología como estudio de los datos del espíritu, psicofísica y psicología fisiológica, psicología del comportamiento, neuropsicología y psicología como ciencia de la personalidad. Una modificación de este esquema, cuya representación gráfica puede verse en la Figura 1, nos sirve para diferenciar la psicología según que enfoque principalmente a unos u otros fenómenos o a las distintas relaciones entre ellos: los contenidos de conciencia (Wundt, Kulpe, Messer), las relaciones entre los datos de la experiencia interior y el organismo (psicofisiología de Helmholtz, Muller y también Wundt), las relaciones entre la estimulación exterior y la experiencia interior (psicofísica de Fechner), la relación entre estímulos y respuestas (Watson, Skinner), las relaciones entre los estímulos, el organismo y las respuestas (Woodworth, Lashley, Osgood), y las relaciones entre las tres esferas, es decir, entre los estímulos ambientales, el constructo de la personalidad, que incluye variables cognitivas y propositivas, y las respuestas observables (Tolman, Miller, Galanter y Pribram y la mayor parte de la psicología actual).

La diversidad de orientaciones se hace, pues, patente tanto a nivel macroteórico como microteórico. Así, encontramos una psicología como ciencia frente a una psicología como humanismo (Koch, 1961); una psicología clínica frente a una psicología experimental (L'Abate, trad. 1967); una psicología experimental, frente a una correlacional (Cronbach, 1957); etc, etc. Las dimensiones de Coan (1968), las prescripciones de Watson (1967) y las estructuras de Wertheimer (1972), ponen de relieve la radical diversidad de la psicología. (Aunque precisamente estos análisis permiten ordenar y simplificar un poco este enmarañado campo, como veremos en el próximo apartado.)

El enfoque paradigmático también avala la radical diversidad de la picología. Aceptando que la psicología haya alcanzado el estado de ciencia paradigmática, hemos de aceptar la sucesión de paradigmas: estructuralista, conductista y el propuesto por Chomsky para la psicolingüística (Palermo, 1971), estructuralista y conductista (Weimer y Palermo, 1973), conductista y cognitivo (Gilgen, 1970; Nudler, 1975; Lachman, Lachman y Butterfield, 1979; seminario sobre Problemas actuales de la Psicología científica en la Fundación March, 1979). Si la psicología se encuentra en un estado preparadigmático (Watson, 1967; Warren, 1971; McKenzie, 1972, Finkelman, 1978; Farrell, 1978), la dispersión y el enfrentamiento entre escuelas, teorías y orientaciones se da por definición -y se comprueba por simple observación-. Cabe 
considerar a la psicología como ciencia multiparadigmática (Buss, 1979, Caparrós, 1978; Mayor, 1980; en cierto modo, Leahey, 1980) en cuyo caso la diversidad de paradigmas plantea serios problemas a todo intento de definir unitariamente la psicología.

\section{Progresiva unificación de la Psicología}

Dado el casi caótico aspecto que presenta, según acabamos de exponer, cabe preguntarse si es posible poner orden en esta confusa maraña.

Sin negar el hecho básico de la diversidad, hemos de contestar afirmativamente $y$, para aclarar esta aparente contradicción, vamos a aportar una serie de datos y de opiniones tan incontestables, creemos, como las anteriores.

La superación de esa diversidad parece que sólo podría producirse mediante un análisis estructural que organizara de algún modo los distintos elementos, o a través de una actitud ecléctica y tolerante, o en base a un esfuerzo teórico de integración y de síntesis o bien tomando la decisión de limitar el campo, es decir, otorgando a una parte de la psicología el alcance de representarla en exclusiva y considerando al resto como ajeno a la misma.

A) Si nosotros pretendemos ahora ordenar la confusa diversidad de escuelas, especialidades, métodos, modelos, rasgos, dimensiones, paradigmas y orientaciones de la psicología, agrupándolos en una serie de dicotomías que contribuyan a su simplificación, podemos ser tachados de arbitrarios y aprioristas, sin embargo, tal pretensión está muy lejos de ser original o aislada: pro el contrario, ha sido casi una constante desde el momento (años treinta) en que se tomó conciencia del problema de las "psicologías".

Ya en 1935 hablaba Lewin de un modo de pensamiento aristotélico frente a otro galileano.

Bruner y Allport, en 1940, descubren en las revistas de psicología de 1888 a 1938 una orientación empírica (mecanicista, cuantitativa, nomotética y operacional) frente a una orientación racional (teleológica, cualitativa, idiográfica, sinóptica y no operacional).

Allport, en 1955, volvía a insistir en dos alternativas: una, lockeana (conductista, periferialista, molecular), que considera al organismo como algo reactivo, y otra, leibniziana, que, por el contrario, considera el organismo como activo y autopropul-
sado.

Obsérvese que casi todas las referencias que hemos hecho a la diversidad en el apartado anterior adoptan también formulación dicotómica.

Recogiendo en parte todo esto y rechazando la existencia de un paradigma en la psicología, Watson propone en 1967 una serie de 18 pares de prescripciones que orientan histórica y sistemáticamente este complejo panorama: mentalismo consciente mentalismo inconsciente; objetivismo (datos conductuales) - subjetivismo (estructuras mentales); determinismo - indeterminismo; empirismo - racionalismo; funcionalismo (actividades) - estructuralismo (contenidos); inductivismo - deductivismo; mecanicismo - vitalismo; objetivismo metodológico (no abierto a la verificación exter- 
na) - subjetivismo metodológico (no abierto a la verificación externa); molecularismo molarismo; monismo - dualismo; naturalismo (trascendiendo los principios de la naturaleza) - supernaturalismo (trascendiendo los principios de la naturaleza); nomoteticismo (leyes generales) - idiografismo (búsqueda de lo individual e irrepetible); periferialismo - centralismo; purismo (el conocimiento por sí mismo) utilitarismo (en función de otras actividades); cuantitativismo - cualitativismo; racionalismo - irracionalismo; estaticismo (perspectiva transversal) - evolucionismo (perspectiva longitudinal); estaticismo (factores permanentes) - dinamicismo (factores cambiantes).

En 1968, Coan pretende evitar el sesgo que cada autor puede introducir en la definición de las dimensiones de la teoría psicológica y para ello recurre al juicio de 232 expertos en historia de la psicología para caracterizar, sobre una escala de cinco puntos, a 54 grandes psicólogos de acuerdo con 34 variables de contenido, metodología, supuestos y modos de conceptualización. Aplicando el análisis factorial a esta matriz de calificaciones encuentra seis factores bipolares de primer orden:

a. - Subjetivismo (procesos conscientes e inconscientes, informes introspectivos, voluntarismo, finalismo, especulaciones) - objetivismo (conducta observable, determinismo, mecanicismo, definiciones operacionales, determinantes biológicos).

b. - Holismo (organización total, unicidad del individuo, observación naturalista, determinantes sociales) - elementalismo (molecularismo, determinismo, mecanicismo).

c. - Transpersonalismo (nomotética, analogías físicas, determinantes inmediatos extcrnos, control experimental rígido) - personalismo (rasgos persistentes, unicidad del individuo, determinantes sociales).

d. - Cuantitativismo (análisis estadístico, descripción y formulación cuantitativa, generalización normativa, control experimental rígido, definición operacional) cualitativismo (factores emotivos, procesos inconscientes, especulaciones).

e. - Dinámicismo (motivación, influencia de la experiencia pasada, entidades hipotéticas, determinantes sociales) - estaticismo (sensación y percepción, informes introspectivos, descripción cuantitativa).

f.-Endogenismo (determinantes biológicos, herencia, analogías físicas, observación naturalística) - exogenismo (determinantes sociales, aprendizaje, definición operacional).

Estos factores están interconectados de tal forma que resultan dos pares de factores de segundo orden:

1.- Orientación sintética (subjetivismo, holismo, orientación cualitativa) - orientación analítica (objetivismo, elementalismo y orientación cuantitativa).

2.- Orientación funcional (dinamicismo, personalismo, endogenismo) - orientación estructural (estaticismo, transpersonalismo, exogenismo).

Estos dos pares de factores de $2^{2}$ orden se redujeron a un superfactor dicotómico: orientación teórica fluida (sintética y funcional) y orientación teórica restrictiva (analítica y estructural).

En la Figura 2 puede verse el esquema de la jerarquía bipolar de variables teóricas y en la Figura 3 se reproduce el cluster jerárquico de los 54 teóricos estudiados.

En su libro de 1979, Coan propone un inventario (Theoretical Orientation Survey) de 63 items, que comprenden escalas de 8 factores, para evaluar los rasgos de las 
diferentes "psicologías".

En 1972 Michael Wertheimer dedica un libro entero, Fundamental Issues in Psychology, a analizar la estructura dicotómica de la psicología.

Agrupa los problemas sustantivos en una serie de alternativfas enfrentadas:

a) El hombre como dueño de su destino (Rogers) y el hombre como víctima (Skinner).

b) El hombre como Dios (Fromm) y cl hombre como demonio (Frcud).

c) El adsum (lo asociativo y sumativo) y el transsum (lo gestáltico).

d) La mente (mentalismo, idcalismo) y el cuerpo (fisicalismo, materialismo).

e) La subjetividad (experiencia) y la objetividad (conducta).

f) El pasado (neoconductismo) y el presente (Lewin).

g) La naturaleza (nativismo, maduración) y la crianza (empirismo, aprendizaje).

h) La complejidad y la simplicidad.

Los problèmas de carácter metodológico también se organizan en pares dicotómicos:

a.- La fertilidad (observación, comprensión, intuición, lo cualitativo, lo idiográfico, lo clínico) y la precisión (lo experimental, la predicción y el control, lo cuantitativo, lo nomotético y lo científico).

b.- El predominio de la teoría (lo formal, lo deductivo, los modelos, la causa, lo absoluto) y el predominio de los datos (lo empírico, lo inductivo, la concomitancia, lo probabilístico).

Para Newell (1973) la psicología se guía a medio nivel, para investigar los fenómenos de bajo nivel, por la construcción de oposiciones binarias tales como: 1) naturaleza vs. crianza, 2) periférico vs. central, 3) aprendizaje uniproceso vs. proceso doble (Charlow), 4) aprendizaje continuo vs. todo-nada, 5) memoria única vs. memoria doble - a corto y a largo término-(Melton), 6) práctica en masa vs. distribuida, 7) procesamiento serial vs. paralelo, 8) investigación exhaustiva vs. autolimitada, 9) lógica espacial vs. estructura profunda, 10) análogo vs. digital, 11) código único vs. códigos múltiples, 12) interpretación contextual vs. independiente, 13) olvido por desuso vs. por interferencia, 14) desarrollo por estadios vs. continuo, 15) gramáticas innatas vs. aprendidas (Chomsky), 16) existencia vs. no existencia del aprendizaje latente, 17) Existencia vs. no existencia de percepción sublimal, 18) gramáticas vs. asociaciones verbales, 19) conciencia vs. inconsciente, 20) rasgos vs. patrones, 22) motora vs. percepción pura en aprendizaje perceptual, 23) aprendizaje sobre ensayos correctos vs. sobre ensayos errados, 24) preatención vs. atención.

Para terminar, y desde una perspectiva diferente, si nos acercamos a medios de difusión científica como son las revistas, encontramos, por ejemplo, que las revistas duras Journal of Comparative and Physiological Psychology, Journal of Experiemental Psychology y American Journal of Psychology- sólo reservan un 3\% del total de sus citas para las revistas blandas y éstas - Journal of Abnormal and Social Psychology. Journal of Personality y Journal of Consulting Psychology- sólo incluyen un $10 \%$ de citas correspondientes a las revistas duras. Parece claro que estos datos reflejan la existencia de dos comunidades científicas diferentes. (Lawer y Lawer, 1965).

Esta persistente estructura dicotómica en el ámbito de tantos y tantos niveles, planos y dimensiones sugiere dos cosas:

a) La mitad de los factores de las series bipolares son isomórficos o compatibles o 
estrechamente relacionados, incluso implicados entre sí; y lo mismo ocurre con la otra mitad.

b) Esta antinomia constante es indicio inequivoco de la existencia de dos psicologías aparentemente diferentes y contrapuestas.

B) Ahora bien, aceptar la dualidad de psicologías significa dejar sin resolver el problema de la unidad. La reducción a la unidad se podría lograr por dos procedimientos: integrar ambas a través de fórmulas eclécticas o generalizadoras o dialécticas: aceptar que la psicología se identifique con una de ellas y marginar a la otra de su campo específico a través del rechazo o el desdén sistemático.

1.- Veamos ahora algunos de los intentos integradores.

-De una manera implícita, y en ocasiones explícita, se concibe la psicología como una mera yuxtaposición de estas perspectivas antinómicas.

Ya en 1937 Allport abogaba por un estudio, tanto de los rasgos individuales como de los rasgos comunes de la personalidad (psicología idiográfica y nomotética). Tyler (1981) alude al lento y progresivo reconocimiento de la individualidad como objeto de la psicología y Epstein $(1980$, p. 802) reconoce y explicita las ventjas de combinar el enfoque idiográfico-nomotético sobre la elección entre uno y otro enfoque.

Para Canestrelli (1968), la psicología debe estudiar, tanto la relación externa entre estímulos y respuestas, como la significación subjetiva inherente al comportamiento.

Taylor (1964) y Boden (1972) admiten junto a las explicaciones mecanicistas, y precisamente en razón de sus insuficiencias, las explicaciones teleológicas.

Lagache (19679) defiende la complementariedad de la psicología experimental y de la clínica.

Kendler (1981, p. 867) reconoce la existencia de dos distintos y legítimos objetos de la psicologia: la experiencia consciente y la conducta objetiva. La investigación de ambos difiere metodológicamente, aunque es posible ampliar la psicología conductual para incluir en ella los análisis de los procesos experienciales, para investigar la conducta subjetiva (p. 99), con lo que se abre la vía a la investigación de las dos perspectivas.

Stevens (1951) ha intentado fundar una psicofísica subjetiva.

Miller, Galanter y Pribram (1960), que se autoproclaman behavioristas subjetivos, insisten en "integrar la subjetividad y el organismo en la unidad y continuidad personal del individuo".

Cronbach (1957) propone un modelo de disciplina psicológica unificada que permita predecir desde la experiencia pasada o desde las presentes características del organismo o desde la combinación de ambas, lo que implica un integración de las dos disciplinas de la psicología científica, la experimental (que estudia la varianza entre tratamientos) y la correlacional (que estudia la varianza entre organismos).

- Cabría también considerar que se produce una integración de las diversas dicotomías cuando la psicología se integra en teorías generales como el fisicalismo, la teoría general de sistemas, la dialéctica, el estucturalismo, la epistemología genética, etc. En efecto, cada una de estas teorías tiende a defender la unidad de la ciencia e incluso del saber en general, lo que supondría a fortiori la unidad del conocimiento psicológico. Sin embargo el problema sigue sin resolverse, basta para ponerlo de 
relieve con preguntar por el criterio que decide entre esas distintas teorías generales, ya que difieren a veces radicalmente. ¿Cuál es la válida y correcta? No es fácil encontrarlo, y ello nos lleva a pensar, de momento, en un cierto pluralismo metodológico y epistemológico; con lo que, por este camino, la posibilidad de integración se desvanece.

En cualquier caso, tanto estos intentos de integración, como -en mayor medidala mera yuxtaposición a que aludíamos antes, no están exentos de una fuerte tensión interna entre las distintas perspectivas o enfoques que se yuxtaponen o integran. $Y$ esta tensión es para nosotros la clave para comprender la situación actual de la psicología, como veremos próximamente en el siguiente apartado.

2.- La alternativa reduccionista recuerda un tanto la actitud de las escuelas en la primera mitad del siglo.

-En 1937, pero reafirmándolo sorprendentemente en 1973, Keller habla de un sistema de psicología como de "una estructura lógica dentro de la que pueden ser ajustados los hallazgos de la ciencia", pero también de que "un sistema puede ser considerado como una definición elaborada", que "determina o fija los límites de la ciencia y al mismo tiempo clarifica su significado" (p. 141). "La definición de psicología más satisfactoria hoy es la del conductismo radical" (p. 143).

Recordemos sin embargo cómo se ha producido en algunos autores un desplazamiento del objeto de la psicología desde la conducta a la conciencia. "No estoy de acuerdo con que el objeto de la psicología sea el comportamiento. El objeto de la psicología es la conciencia. El conocimiento del comportamiento no es el fin de nuestra ciencia, sino el medio" (Teplov, citado por Zazzo, 1969 trad. 1970, p. 89).

El mismo Fraisse (p. 60) propone "definir la psicología como ciencia de la psique, más que como ciencia del comportamiento", pues aunque reconoce que los comportamientos son la materia prima de la psicología (p. 52), sin embargo todos ellos se remiten a un centro de elaboración (psique) que los produce y controla a través de circuitos directos y circuitos simbólicos (p. 53).

Los mismo tendríamos que decir del reduccionismo de la psicología a ciencia natural (Telford y Sawrey, 1972), frente al que se ha levantado el reduccionismo a ciencia social (harrison, 1972); el de la psicología experiemental frente a la clínica y viceversa, (L'Abate, 1967; Dana, 1966; Meehl, 1954; Holt, 1958...) etc, etc.

Las docotomias del párrafo anterior han dado origen o han surgido de actitudes reduccionistas de este tipo.

- Convendría, para terminar, aludir a dos de los más importantes reducionismos que se han dado en psicología, el psicofisiológico (Jessor, 1958) y el fisicalista (Block, 1980), que tienen un tratamiento más adecuado al abordar el problema de las relaciones interdisciplinares de la psicología, aunque tienen repercusión sobre su situación intradisciplinar porque suponen, en efecto, una reducción de la psicología.

- Cabría considerar que la psicología ha alcanzado el estadio de ciencia normal, en cuyo caso la unificación de la disciplina comno tal se lograría a trevés del paradigma dominante $o$ de la matriz disciplinar vigente. Pero esta concepción difícilmente arroja un concepto unitario de la psicología, pues reconoce que a un paradigma o matriz disciplinar le sucede otro a través de un período de crisis y de cambio revolucionario. En dos momentos sucesivos ¿existe el mismo concepto de psicología? En caso afirmativo la concepción básica de la disciplina no cambia y la sustitución paradigmática es in- 
tradisciplinar o accesoria y circunstancial. ¿No existe el mismo concepto de psicología? En caso afirmativo, cabe entonces preguntar cuál de ellos es el correcto y adecuado. $\mathrm{Si}$ se admiten ambos, no es fácil llegar a un concepto unitario. En cualquier caso, el enfoque paradigmático es difícilmente compatible con el intento de obtener un concepto unitario de psicología basado precisamente en las características del paradigma.

\section{Tensión entre pluralismo y unitarismo}

Entre el movimiento hacia un sistema pluralista y hacia un sistema integrador encontramos hoy una fuerte tensión, patente en casi todos los autores, no sólo en relación a la psicología que hacen, sino también en sus reflexiones históricas y epistemológicas.

A) La primera fuente de tensión es la alternativa equilibrada, hoy por hoy, entre los que se orientan a considerar la psicología como un conjunto de disciplinas más o menos convergentes, más o menos paralelas y los que siguen pensando en una disciplina integrada. El conflicto se agrava si tenemos en cuenta el pluralismo epistemológico al que se tiende hoy en la filosofía de la ciencia.

Campos como la psicología sensorial y biológica podrían considerarse como pertenecientes a las ciencias naturales. Pero otros sectores requieren modos de investigación tan próximos a las humanidades como a las ciencias (percepción, cognición, psicología social, psicopatología, personología...).

Fraisse (1978) constata que "la mayor parte de los trabajos - sobre todo americanos- se han orientado hacia los procesos adaptativos en base a circuitos directos"; "desde 1950 y bajo a influencia de psicólogos como J. Bruner y G. Miller en América, de Vigotsky y, sobre todo, de Piaget en Europa, los estudios de las actividades simbólicas, bajo la etiqueta un poco general de psicología cognitiva, se han multiplicado". "Entre estas dos orientaciones hay una tensión que es una de las causas principales de la crisis actual en psicología" (p. 58). Claro que, según su opinión, "la toma en consideración del doble sistema de elaboración (ya descrito) permite evitar uno y otro peligro", el volver al mentalismo o el estar condenado al reduccionismo. Una actitud parecida, en otro campo, es la de Cronbach (1975) o la de L'Abate (trad. 1967).

Todas las posiciones expuestas en los apartados anteriores, las que presentan la psicología como un conjunto de tendencias y campos heterogéneos e irreductibles, y las que consideran que se pùede articular a través de una serie de dicotomías, o las que buscan la integración -yuxtaponiéndolas o sintetizándolas-, coexisten y se interpenetran haciéndose sus límites borrosos, cuando no se enfrentan con vigor o cierta tozudez. Esta realidad sólo puede ser entendida a través de una tensión entre el pluralismo y las tendencias integradoras.

Sin embargo, hasta en esto se encuentran opiniones extremadas junto a otras más matizadas.

La opinión de Koch (1978) es contundente: "cuando se consultan los detalles de los 100 años de historia de la psicología, la tendencia patente es hacia el fraccionamiento teórico y sustantivo (y la creciente insularidad entre las especialidades) y no la integración" (p. 637); "mi posición sugiere que la no cohesividad de la psicología sea final- 

mente reconocida, reemplazándola por alguna locución tal como estudios psicológicos"
(p. 638).

Kendler (1970) afirma, en cabio, que "una psicología unificada no existe hoy y no hay garantía de que alguna vez será alcanzada", pero tampoco está más allá de los límites de la posibilidad. Dependerá de si la comunidad científica acepta un criterio que permita evaluar los méritos de las distintas interpretaciones competidoras. El marco de referencia más probable es el que incluya un componente deductivo. La unidad dependerá del ingenio de los futuros psicólogos para crear teorías que integren la conducta, la experiencia fenoménica y los eventos neurofisiológicos. Si tal no ocurre, la psicología como disciplina se' dividirá inevitablemente (reproducido en Marx y Goodson, 1976, pp. 623-4).

B) Según Marx y Goodson (1976, p. 572) la psicología de hecho permanece segmentada en torno a su objeto y a su método. Los intentos de solución han sido: la exclusión (Titchener, los conductistas); la subsunción, es decir, la reducción a fisiología; y la inclusión, como proponen Goodson y Morgan (p. 394-407) o el mismo Kendler, de los tres niveles de análisis: experiencial, fisiológico y conductual.

Kendler (1981, p. 299) reconoce que existe desacuerdo acerca de la naturaleza de la psicología y del papel que juega en la sociedad, pero señala algunos rasgos que la caracterizan actualmente y que lo harán probablemente en el futuro: preferencia por interpretaciones neurofisiológicas, cultivo de la psicología social en settings naturales y desarrollo del paradigma del procesamiento de información, continuación de la psicoterapia y mantenimiento de las dos controversias (holismo/atomismo, racionalismo/empirismo). Recordando su trabajo sobre "The unity of Psychology" del año 1970, se considera ingenuo al haber pretendido que el marco de referencia más aceptable sería el que requiriera un componente deductivo. A la altura de 1981, piensa más bien que la metodología de la ciencia natural no ha tenido éxito $y$, aunque lo ha tenido en parte, se mantiene la necesidad de otros enfoques: la psicología es un estudio multidisciplinar con diferentes objetos y una gran variedad de supuestos epistemológicos e intentar reconciliarlos y homogeneizarlos puede llevarnos a perder las virtudes de cada uno de ellos en particular.

Desde una perspectiva Kuhniana, la tensión entre unidad y diversidad se resuelve en la sucesión de paradigmas, de periodos de ciencia normal y de crisis revolucionarias. Aunque no queda claro en esta concepción si cambia todo o lo sustancial, en cuyo caso se plantea el problema de la pertenencia de los sucesivos paradigmas a la misma disciplina o a otras diferentes, o si la sustancia de la disciplina permanece, en cuyo caso la diversidad es meramente accesoria -temática o metodológicamente-

Los inevitables cambios en el desarrollo de la psicología podrían justificar perfectamente su diversidad si se entendieran, según propone Coan $(1979,64-5)$, como cambios de nivel en una dimensión determinada (desplazamiento en la tendencia central o en la relevancia), cambios en el objetivo del sistema (hacia su expansión o su restricción) y cambios en la composición del sistema (por reemplazamiento, convergencia o integración, divergencia o desintegración y reorganización). Todo esto -salvo lo del reemplazamiento- permite articular la unidad y diversidad de la psicología mejor que el más global y radical enfoque de Kuhn. Una buena parte de las propuestas de estas 
tensiones entre unidad y diversidad -el campo de Darden, el dominio científico de Shapere, el programa de investigación de Lakatos, la disciplina de Toulmin-, sobre todo cuando reconocen la conveniencia de armonizar de alguna forma la necesidad de una justificación racional -que predispone a la unidad- con la real y cambiante situación del descubrimicnto -que recoge o favorece la diversidad.

Piaget, por su parte, reconoce esta tensión entre unidad y diversidad: "si bien no cabe duda de que hoy en día hay una tendencia a la unificación,... sin embargo, no deja de ser cierto que dicha unificación es un programa de cara al futuro más que una realidad" (Piaget, 1970, trad. 1973, 134). La diversidad de interpretaciones no se asienta en la discusión de las leyes, ni tampoco en la deducción de las mismas; "la verdadera razón hay que buscarla en la diversidad de modelos posibles, ya que la vida mental tiene su origen en la vida orgánica, se desarrolla en la vida social y se manifiesta por medio de estructuras múltiples", de ahi que existan diversidad de modelos según que dominen los ensayos reduccionistas de carácter organicista, fisicalista, sociológico, etc., (Ibid, p. 135).

Al explicitar las diferencias entre una psicología nomotética (que pretende descubrir leyes, sistemas de relaciones, estructuras) y una naturalista ideográfica, habría que decir (que persigue alcanzar los organismos existentes realmente en la naturaleza), Reuchlin (1981, p. 109 y 114) concluyen que no le "parece natural dividir a los psicólogos en dos grupos extraños el uno al otro"; la opción entre una y otra "crea más bien en el seno de cada una de las especialidades de la psicología y quizá en el espíritu mismo de ciertos psicólogos una bipolaridad, en cierto casos una tensión, que puede suscitar (un verdadero) progreso". En el resumen que Chiland (1981, pp. 131-5) hace de la discusión sobre la unidad de la psicología late la misma tensión, aunque se observa una clara tendencia a reconocer la diversidad relativa al objeto, a la metodología y a la práctica profesional.

Más explícitos en la forma de articular la diversidad y la unidad se manifiestan Rychlak (1977) y Marceil (1977), entre otros. Para el primcro, es esencial en la ciencia combinar la tradición "dialéctica", que da cuenta de la creación y formación de los supuestos y métodos científicos a través de un pensamiento libre, creativo, inestructurado, y la tradición "demostrativa", que se ocupa de las implicaciones lógicas de la ciencia y de los medios de intercomunicación, lo que sólo puede hacerse a través de formas y estructuras más rígidas. Para el segundo, la diversidad y contradicción en el plano teórico es compatible con el acuerdo sobre la validación metodológica.

C) Un ejemplo de como puede representarse la tensión dinámica, en torno al objeto y al método de la psicología, entre una psicología científico positiva en sentido estricto y una psicología humanística en sentido amplio, lo tenemos en los esquemas de Mayor (1980) que se reproducen en las Fig. 4 y 5.

Por último, cabe aceptar una concepción sistemática (orchard, 1978) como base para integrar dinámica y estructuralmente los diversos elementos del sistema, los diversos niveles de análisis y las diversas teorías, lo que permite resolver el dilema al articular la unidad y la diversidad (Mayor y Pćrcz Ríos, en prensa). 


\section{Conclusión}

$\mathrm{Ni}$ que decir tiene que no podemos dar por válidos ninguno de los términos lemáticos que pretenden resolver el problema de la identidad de la psicología. Aceptar sin más la diversidad, tal como la hemos mostrado, nos lleva a rechazar la existencia de la psicologia; a lo más a lo que podría llegarse es a admitir la coexistencia de diversos estudio psicológicos, de múltiples intentos inmaduros de configurar otras tantas disciplinas. Optar por un concepto unificado de psicología, por el momento, nos lleva al reduccionismo, lo que significa reconocer el carácter de psicología propiamente dicha a una opción, rechazando ese carácter para todas las otras opciones, o a un vago eclecticismo que por comodidad mental ha sido adoptado con frecuencia, aunque en última instancia nos retrotrae a la alternativa de la diversificación.

Queda por tanto, como única posición acorde con la realidad de la psicología, tal como se manifiesta racional y sociohistóricamente, la de admitir la tensión entre su unidad y su diversidad.

Ahora bien, esa tensión puede ser dinámica, dialéctica e inestable, dejando a la compleja actividad de la comunidad científica la responsabilidad de los ajustes y desajustes, de los equilibrios y desequilibrios entrre unidad y diversidad (contexto de descubrimiento), o bien esa tensión puede ser estructural o sistemática, articulándose la diversidad de planos, niveles y dimensiones en un sistema epistémico que haga compatible el pluralismo metodológico, el multiparadigmatismo con una concepción unitaria del saber y de la praxis psicológicos (con texto de justificación). Por el momento, parece funcionar la psicología como sometida a la tensión dialéctica e inestable a que hemos aludido. Sin embargo, parece aumentar cada vez más la presión por lograr una concepción de la psicología como sistema epistemico en el que quepan diversos planos, enfoques, paradigmas, teorías y métodos. 
TABLA 1: Medidas de 68 juicios sobre 36 dimensiones de 5 escuelas de Psicología (FUCHS y KAWASH, 1974)

\begin{tabular}{|c|c|c|c|c|c|}
\hline & Conductismo & Funcionalismo & Gestalt & Psicoanálisis & Estructuralismo \\
\hline Centralismo & 3,07 & 4,35 & 5,75 & 5,82 & 5,25 \\
\hline Cualitativismo & 1,86 & 3,46 & 5,12 & 5,48 & 4,26 \\
\hline Cuantitativismo & 6,28 & 4,62 & 3,34 & 1,68 & 4,91 \\
\hline Deductivismo & 3,27 & 3,24 & 3,93 & 4,65 & 3,38 \\
\hline Determinismo & 6,66 & 4,93 & 4,72 & 6,15 & 5,37 \\
\hline Dualismo & 1,54 & 3,38 & 3,53 & 3,85 & 4,70 \\
\hline Dinamicismo & 3,85 & 4,94 & 4,85 & 6,01 & 2,18 \\
\hline Empirismo & 6,28 & 5,63 & 4,57 & 4,12 & 5,81 \\
\hline Estaticismo 1 & 3,52 & 3,19 & 3,51 & 2,00 & 5,22 \\
\hline Estaticismo 2 & 3,66 & 3,12 & 3,31 & 3,07 & 5,35 \\
\hline Estructuralismo & 1,86 & 2,44 & 3,34 & 3,88 & 6,90 \\
\hline Evolucionismo & 4,75 & 5,19 & 3,91 & 5,87 & 2,01 \\
\hline Funcionalismo & 4,84 & 6,84 & 4,13 & 4,41 & 2,07 \\
\hline Idiografismo & 2,37 & 3,40 & 3,56 & 5,97 & 2,19 \\
\hline Indeterminismo & 1,54 & 2,47 & 3,06 & 1,93 & 2,12 \\
\hline Inductivismo & 5,91 & 5,41 & 4,68 & 4,18 & 5,43 \\
\hline Irracionalismo & 2,58 & 3,03 & 3,09 & 6,48 & 2,13 \\
\hline Mecanicismo & 6,33 & 4,06 & 3,56 & 3,68 & 4,06 \\
\hline Mentalismo cons. & 1,73 & 4,60 & 5,07 & 3,68 & 6,41 \\
\hline Mentalismo incons. & 1,63 & 2,82 & 2,85 & 6,81 & 2,13 \\
\hline Molarismo & 2,82 & 4,54 & 6,44 & 5,19 & 2,43 \\
\hline Molecularismo & 5,73 & 3,41 & 1,79 & 2,60 & 5,96 \\
\hline Monismo & 6,22 & 3,50 & 3,88 & 3,56 & 2,87 \\
\hline Nativismo & 2,01 & 2,91 & 4,04 & 3,31 & 3,06 \\
\hline Naturalismo & 6,51 & 5,63 & 5,35 & 5,19 & 5,48 \\
\hline Nomoteticismo & 6,46 & 5,40 & 5,50 & 4,57 & 5,98 \\
\hline Objetivismo & 6,43 & 4,82 & 3,43 & 2,78 & 2,65 \\
\hline Objetivismo metod. & 6,85 & 5,01 & 4,50 & 2,50 & 3,87 \\
\hline Periferalismo & 5,58 & 3,93 & 2,68 & 1,98 & 3,24 \\
\hline Purismo & 4,46 & 3,18 & 4,94 & 2,91 & 5,81 \\
\hline Racionalismo & 3,37 & 4,07 & 4,72 & 2,87 & 4,51 \\
\hline Subjetivismo & 1,40 & 4,13 & 5,10 & 5,93 & 5,90 \\
\hline Subjetivismo metod & 1,25 & 2,82 & 3,15 & 5,43 & 4,25 \\
\hline Supernaturalismo & 1,15 & 1,50 & 1,62 & 1,87 & 1,43 \\
\hline Utilitarismo & 5,06 & 5,74 & 3,22 & 5,28 & 2,37 \\
\hline Vitalismo & 1,49 & 2,44 & 2,91 & 3,56 & 2,48 \\
\hline
\end{tabular}


TABLA 2: Factores comunes a la matriz de puntuaciones sobre las 36 dimensioncs (correlaciones superiores a .50) (FUCHS y KAWASH, 1974)

\begin{tabular}{|c|c|c|c|c|c|c|c|}
\hline Dimensiones & 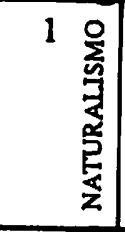 & 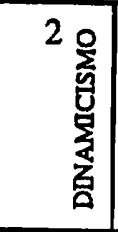 & 3 号 & 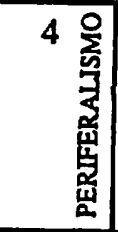 & 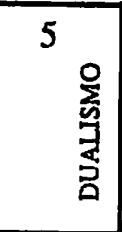 & 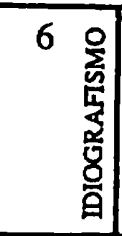 & 7 离 \\
\hline $\begin{array}{l}\text { Deductivismo } \\
\text { Dualismo } \\
\text { Dinamicismo } \\
\text { Empirismo } \\
\text { Estaticismo 1 } \\
\text { Estaticismo 2 } \\
\text { Estructuralismo } \\
\text { Evolucionismo } \\
\text { Funcionalismo } \\
\text { Idiografismo } \\
\text { Inductivismo } \\
\text { Mecanicismo } \\
\text { Molarismo } \\
\text { Monismo } \\
\text { Nativismo } \\
\text { Naturalismo } \\
\text { Nomoteticismo } \\
\text { Periferalismo } \\
\text { Subjetivismo } \\
\text { Supernaturalismo } \\
\text { Utilitarismo } \\
\text { Vitalismo }\end{array}$ & $\begin{array}{r}.862 \\
.719 \\
\\
.582 \\
-.723 \\
-.604\end{array}$ & $\begin{array}{r}.971 \\
-.614 \\
-.662 \\
.814\end{array}$ & $\begin{array}{l}-.602 \\
.529\end{array}$ & $\begin{array}{l}.597 \\
.796\end{array}$ & .978 & .635 & .579 \\
\hline
\end{tabular}


TABLA 3: Puntuaciones estandardizas de cada uno de los 7 factores para cada una de las cinco escuelas (FUCHS y KAWASH, 1974)

\begin{tabular}{|c|c|c|c|c|c|c|c|}
\hline & 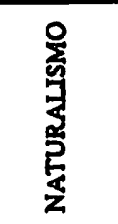 & 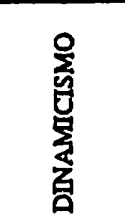 & 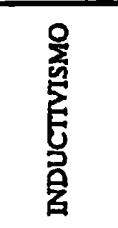 & 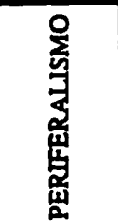 & 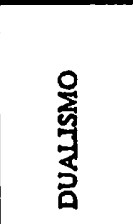 & 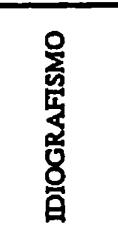 & 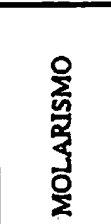 \\
\hline Conductismo & .70304 & -.34115 & .95926 & .79449 & -1.16928 & .07873 & .05149 \\
\hline Funcionalismo & -.10080 & .37886 & .32037 & .92848 & -.12105 & .13791 & .39610 \\
\hline Gestalt & -.22919 & .24805 & -.49005 & -.06710 & .21765 & .01787 & .29669 \\
\hline Psicoanálisis & -.83043 & .80354 & -.68177 & -.88550 & .48305 & .64305 & .17697 \\
\hline Estructuralismo & .45739 & -1.08930 & -.10781 & -.77034 & .60607 & -.87757 & -.92126 \\
\hline
\end{tabular}


Fig. 1: Modelos o esquemas de la psicología

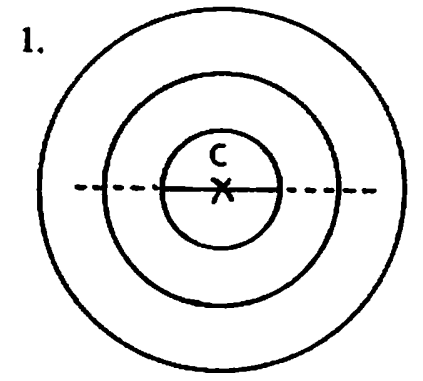

El estudio de los hechos de conciencia

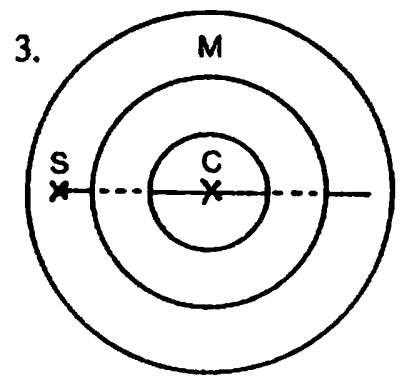

Las relaciones entre los estímulos y la conciencia

5.

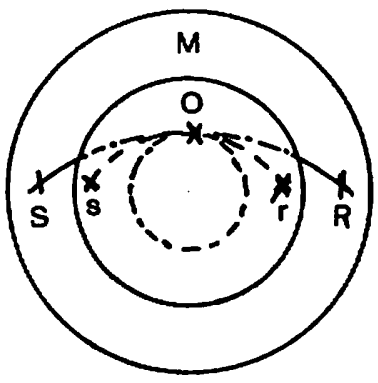

Las relaciones entre los estímulos, el organismo (con $s$ y $r$ ), y los respuestas observables

$S=$ Estímulo externo

$R=$ Respuesta observable

$S=$ Estímulo interno

$r=$ Respuesta interna

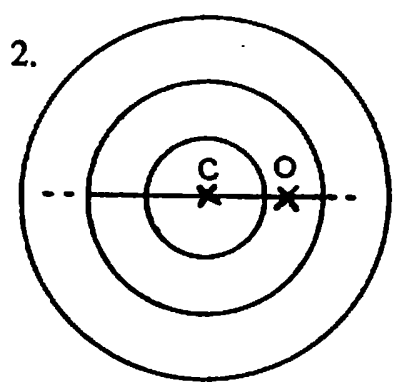

Las relaciones entre conciencia y organismo

4.

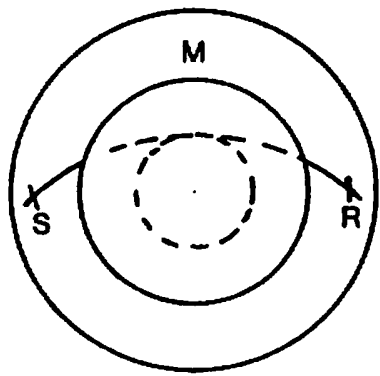

Las relaciones entre los estímulos y las respuestas observables

6.

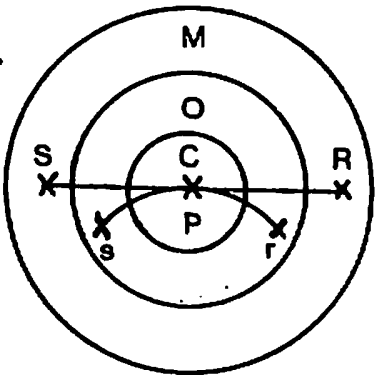

Las relaciones entre los estímulos, la personalidad (organismo consciente, cognición y propositividad, etc.) y las respuestas observables

$\mathrm{C}=$ Conciencia

$\mathrm{O}=$ Organismo

$\mathbf{P}=$ Personalidad

$M=$ Medio (FRAISSE, 1969, Modificado) 
Fig. 2: Esquema de la jerarquía de variables teóricas en Psicología (COAN, 1968)

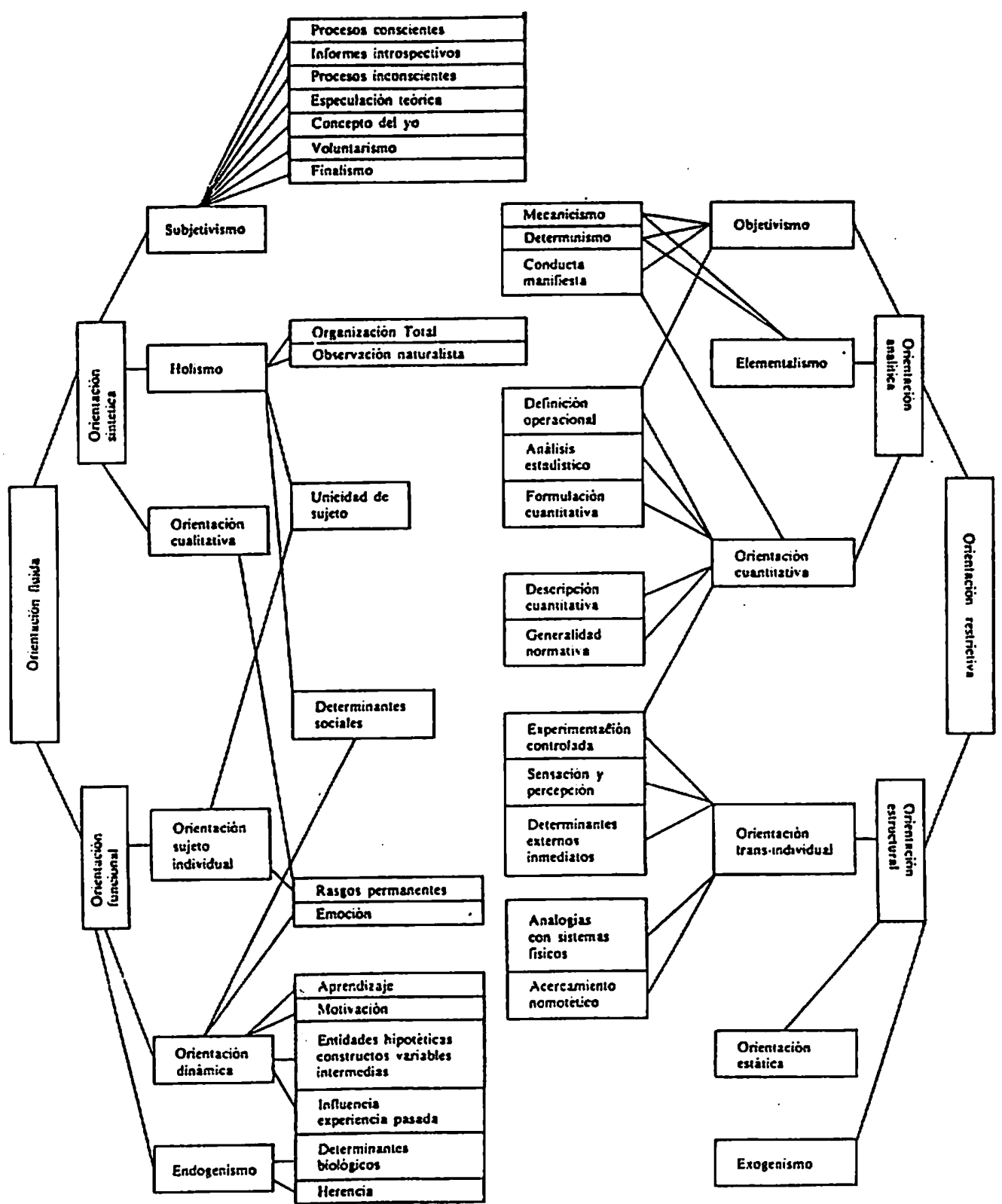

(TOMADO de CARPINTERO, 1976) 
Fig. 3: Cluster jerárgico de 54 teóricos de la Psicología (COAN, 1968)

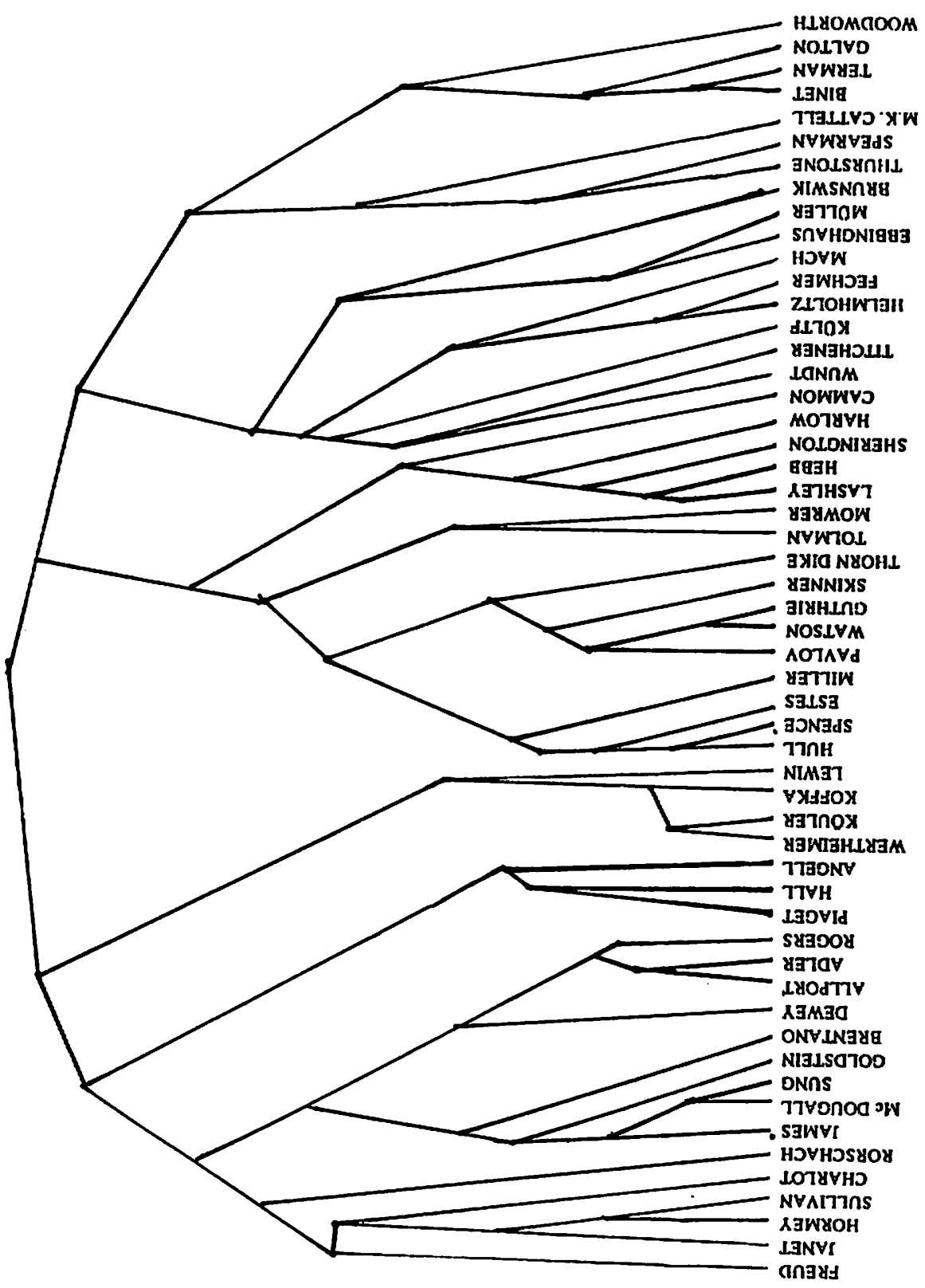


Fig. 4: El objeto de la psicología

\section{PSICOLOGIA HUMANISTA EN SENTIDO AMPLIO}

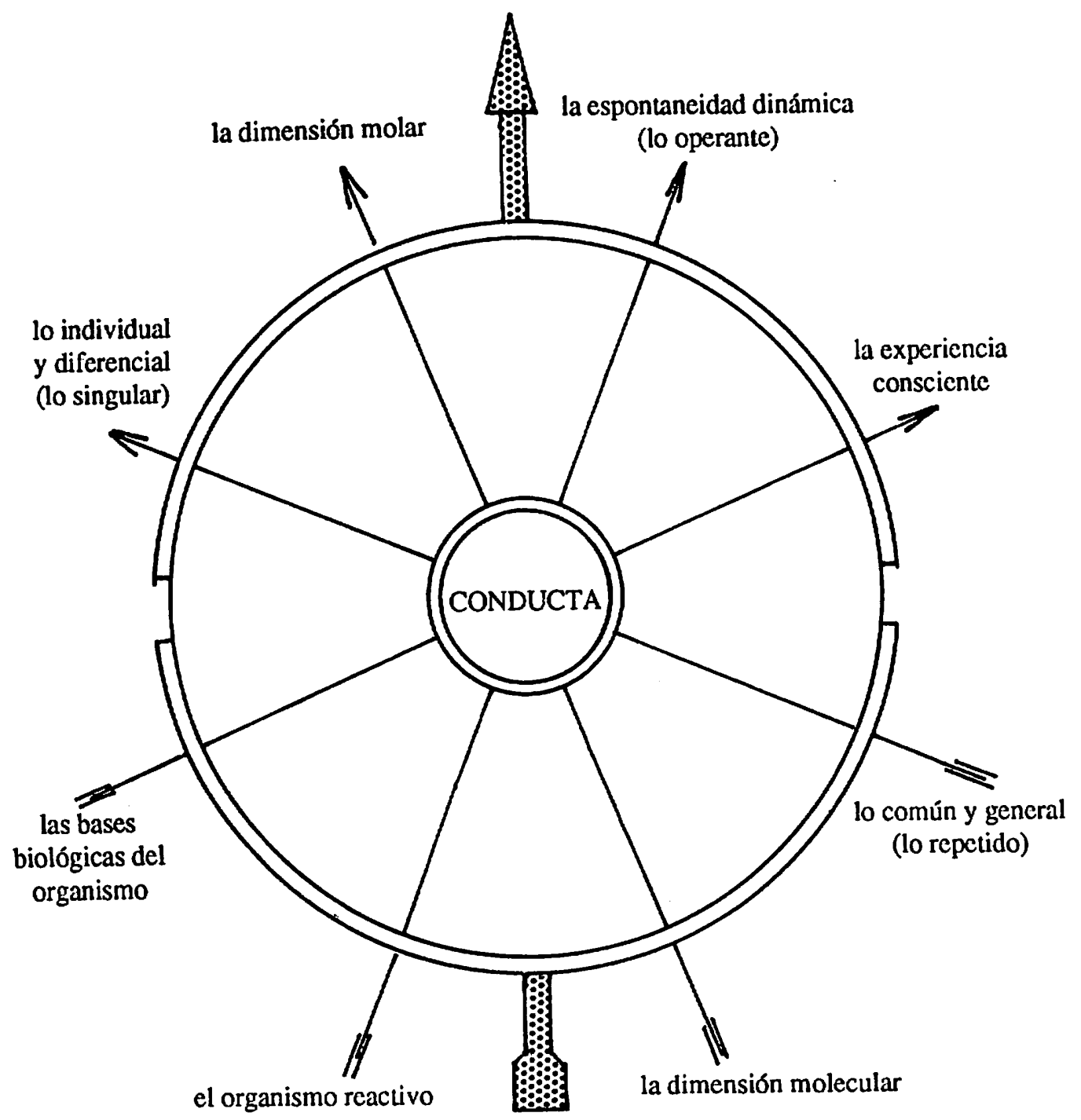

PSICOLOGIA CIENTIFICO-POSITIVA EN SENTIDO ESTRICTO 
Fig. 5: El mélodo Cientúfico-Positivo en Psicología

\section{PSICOLOGIA HUMANISTICA EN SENTIDO AMPLIO}

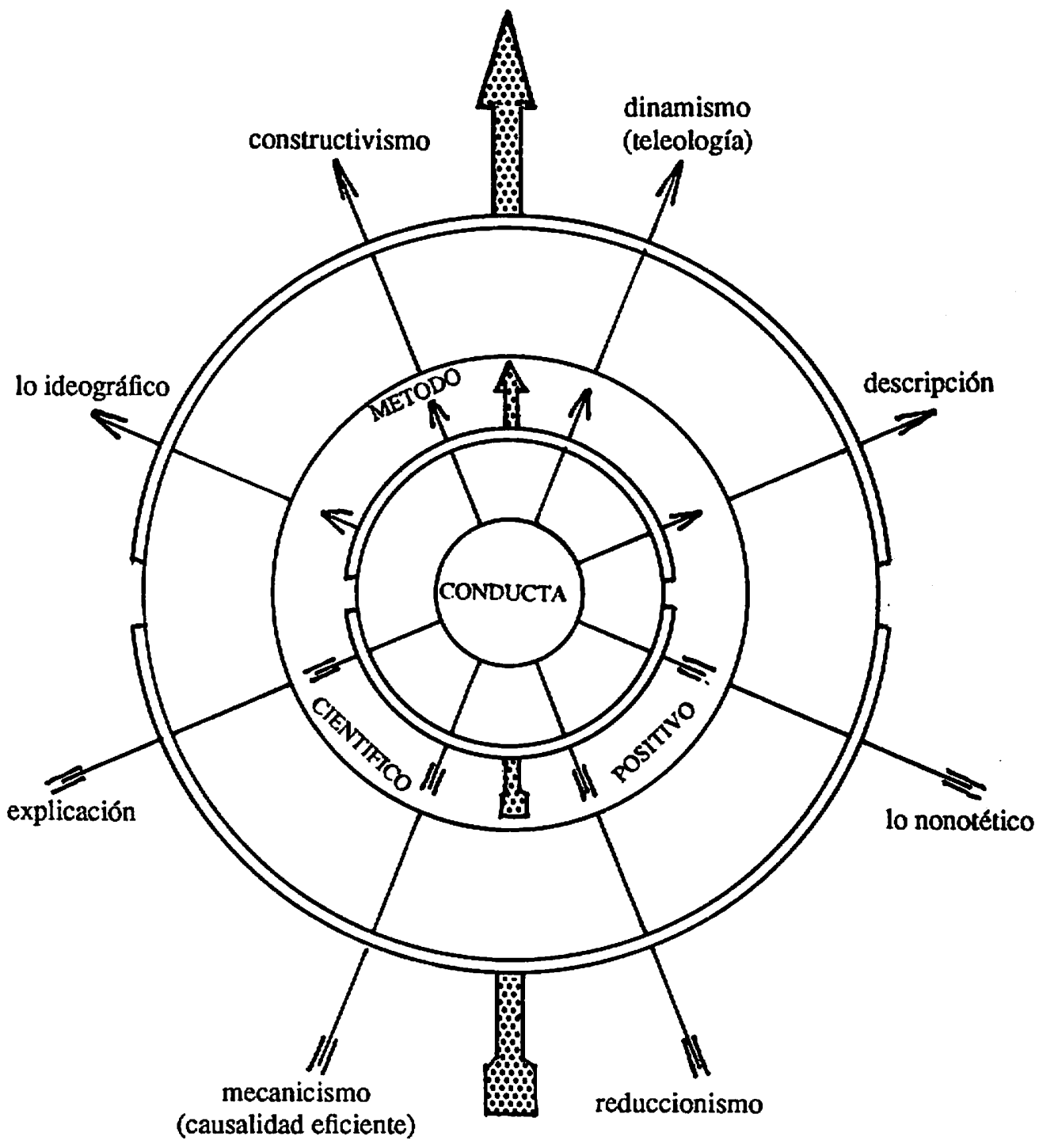




\section{BIBLIOGRAFIA}

ALLPORT, G. W. - Personality. A Psychological Interpretation. Holt, N. York, 1937. (Trad.: Paidós, 1965).

ALLPORT, G. W. - Becoming: Basic Considerations for a Psychology of Personality. Yale Univ. Press, New Haven, 1955.

BARKER, E. N. - "Humanistic psychology and scientific method". Interpersonal Development. 1971-1972, 2. 137-172.

BECK, M. - Psicología. Losada, Buenos Aires, 1947.

BLOCK, N. - Readings in Philosophy of Psychology. Methuen, London, 1980 y 1981. (Vol. 1 y 2).

BODEN, M. - Purposive Explanation in Psychology. Harvard University Press, Cambridge. 1972.

BOLTON, N. (ed.) - Philosophical Problems in Psychology. Methuen, London, 1979.

BRENTANO, F. - Psychologie von Empirischen Standpunke. Dunker und Humboldt, Leipzig. 1874.

BROWN, S. C. (ed.) - Philosophy of Psychology. McMillan, London, 1974.

BRUNER, J. S. and ALPORTG, W. - "Fifty Years of Change in American Psychology". Psychological Bulletin, 1940, 37, 759-776.

BRUNSWIK, E. - The Conceptual Framework of Psychology. Vol. I, n² 10 International Encyclopedia of Unified Science. University of Chicago Press, Chicago, 1952.

BUBER, M. - ¿Qué es el Hombre? F. C. E., Méjico, 1950 (1² ed. hebreo, 1942; 1' ed. inglés, 1948).

BUGENTAL, J. F. T. - Challenges of Humanistic Psychology. McGraw-Hill, N. York, 1967.

BUHLER, K. - Die Krise der Psychologie. Verlag Gustav Fischer, Stuttgart, 1927, 1965 (trad. Morata, 1966).

BUSS, A. - Psychology: Behavior in Perspective. Willey. N. York, 1978.

CANESTRELLI, L. - "La Psicología ciencia de la conducta". En: CANESTRELLI et al.: Le comportement. P. U. F., Paris, 1968.

CASSIRER, E. - Antropología filosofica. F. C. E. Méjico, 1945 (1' ed. inglés, 1944).

CHAPLIN, J. P. and KRAWIEC, T. S. - Systems and Theories of Psychology. Holt, N. York, 1960 (2: ed. 1968).

CHILAND, C. - "Introduction" y "Discussions". Revue de Psychologie Appliquee, 1981, 31-277,78, y $131-161$.

COAN, R. W. - "Dimensions of Psychological Theory". American Psychologist. 1968, 23. 715-722.

CRONBACH, L. J. - "The. Two Disciplines of Scientific Psychology". American Psychologist. 1957, 12, 681-84.

DANA, R. H. - Foundations of Clinical Psychology. D. Van Nostrand Company Holland, 1966. (Trad.: Paidós, 1972).

DILTHEY, W. - "Ideas acerca de una Psicología Descriptiva y Analítica. (1894)". En DILTHEY, W.: Psicología y Teoría del Conocimiento. F. C. E. Méjico, 1945.

DONCEEL, J. F. - Antropologia Filosofica. Carlos Lohle, B. Aires, 1969.

EACKER, J. - Problems of Philosophy and Psychology. Nelson, Chicago, 1975.

ESTES, W. K.; KOCH, S.; McCORQUODALE, K.; MEEHL, P. E.; MUELLER, C. N.; SHOENFELD, W. N. and VERPLANK, W. S. - Modern Learning Theory. AppletonCentury-Crofts, N. York, 1954.

FARRELL, B. A. - "The Progress of Psychology". Br.J. Psychol. 1978, 69. 1-8.

FEIGL, H. and SCRIVEN, M. (eds.): Minnesota Studies in the Philosophy of Science. Vol. The 
Fundations of the Science and the Concepts of Psychology and Psychoanalysis. University of Mennesota Press, Minneapolis, 1956.

FEYERABEND, P. - Against Method: Outline of Anarchistic Theory of Knowledge. En: RADNER and WINOKUR, 1970 (trad: Ariel, 1974).

FINKELMAN, A. - "Science and psychology". Amer. Journal of Psych 1978, 91, 179-199.

FODOR, J. A. - Psychological Explanation. Random House, N. York, 1968.

FRAISSE, P. - "Modéles pour une histoire de la psychologie". Bulletin de Psychologie de L'Université de París, Tome XXII, (1968-69) 276, 9-13, 540-545.

FRAISSE, P. - "Psychology: Science of man of science of behavior". En: XVI st International Congress of Psychology. P. U. F. París, 1978.

FRÖBES, J. - Lehrbuch der Experimentellen Psychologie. Herder \& Co. G. M. B. H. verlagsbuchhandlung, Friburgo, 1923 (trad.: Tratado de Psicologia Empirica y Experimental. Razón y Fe, Madrid, 1944).

FUCHS, A. H. and KAWASH, G. F. - "Perspective Dimension for Five Schools of Psychology". Journal of the History of the Behavioral Sciences, vol. X, 1974, 3. 352-366.

GILGEN, A. R. (ed.); Contemporary Scientific Psychology. Academic Press, N. York, 1970.

GIORGI, A. - Psychology as Human Science: A Phenomenologically Based Approach. Harper and Row, N. York, 1970.

HARRISON, A. A. - psychology as a Social Science. Brooks/Cole Pub. Com., Monterrey, 1972.

HEIDBREDER, E. - Seven Psychologies. Appleton Century-Crofts. N. York, 1933 (trad: Paidós, Buenos Aires, 1960. Apéndice español con siete capítulos).

HOLT, R. R. - "Cinical and Statistical Prediction: A Reformulation and some new Data". Journal of Abnormal and Social Psychology. 1958, 56, 1-12.

HUSSERL, E. - "Philosophie als strenge wissenchaft". Logos, 1910-11, 1 289-314 (trad. esp.: La Filosofía como ciencia estricta. Nova, B. Aires, 1962).

JESSOR, R. - "The problems of redutionism in psychology". Psychological Review, 1958, 65, 170-178. (En: MARX, M. H.: Theories in Contemporary Psychology. McMillan, N. York, 1963).

KEEN, E. - A Primer in Phenomenological Psychology. Holt, N. York, 1975.

KELLER, F. S. - The Definition of Psychology. Appleton. N. York, 1937.

KELLER, F. S. - The Definition of Psychology. Appleton, N. York, 1973. (2 ed.).

KENDLER, H. H. - "The unity of psychology". Canadian Psychologist, 197011 (1), 30-47. (En: MARX, M. H. and GOODSON, F. e.: Theories in Contemporary Psychology. McMillan. N. York, 1976).

KENDLER, H. H. - Psychology: A Science in Conflict. Oxford Univ. Press, New York, 1981.

KOCK. S. - "Psychological sicence versus the science-humanism antonimy: Intimations of a significant sicence of man". American Psychologist. 1961, 16, 629-639.

KOCH, S. - "Psychology and the future". American Psychologist, 1978, 631-647.

KRANTZ, D. L. - Schools of Psychology: A Symposium. Appleton. N. York, 1969.

KRASNER, L. - "The future and the past in the behaviorism-humanism dialogue". American Psychologist, 1978, pp. 799-804.

KUNHN, T. S. - The Structure of Scientific Revolutions. University of Chicatgo Press, Chicago, 1962. (2 ed. ampliada. 1970) (trad.: F. C. E., 1971).

L'ABATE, L. - Principles of Clinical Psychology. Grune and Straton, N. York, (Trad.: Paidós, 1967).

LAGACHE, D. - L'Unité de la Psychologie. P. U. F., París, 1949. (Trad.: Paidós, 1970).

LEAHEY, T. - A History of Psychology (Main Currents in Psychological Thought). PrenticeHall, Englewod-Cliffs. 1980. 
LERSCH. P. - La Estructura de la Personalidad. Scientia. Barcelona, 1958.

LEWIN, K. - A Dynamic Theory of Personality. Mc Graw-Hill, N. York, 1935.

MARC, A. S. J. - Psychologie Reflexive. Desclée de Brouwer, París, 1948. (trad.: Gredos, 1965).

MARCEIL, J. C. - "Implicit dimensions of ideography and nomothesis: A reformulation". American Psychologist, 1977, pp. 1046-54.

MARX, M. H. (ed.) - Psychological Theory: Contemporary Readings. McMillan, N. York, 1951.

MARX, M. H. (ed.) - Theories in Contemporary Psychology. McMillan, N. York, 1963.

MARX, M. H. and GOODSON, F. E. (eds.) - Theories in Contemporary Psychology. Mcmillan, N. York, 1976.

MARX, M. H. and HILLIX, W. A. - Systems and Theories in Psychology. McGraw Hill, N. York, 1963. (Trad.: Paidós, 1967).

MAY, R. (ed.) - Existencial Psychology. Random House, N. York, 1961. (Trad.: Paidós, 1963).

MAYOR, J. - "Orientaciones y problemas de la psicologfa cognitiva". Análisis y Modificación de Conducta, 1980, 6, 11-12, pp. 213-78.

MAYOR, J. - "Actividad humana y procesos cognitivos". En MAYOR, J.: Actividad Humana y Procesos Cognitivos. Alhambra, Madrid, 1985, pp. 3-40.

MAYOR, J. y PEREZ RIOS, J. (en prensa): "Psicología o psicologías". En MAYOR, J. y PINILLOS, J. L.: Tratado de Psicologia General. Tomo I: Historia, Teoría y Método. Alhambra, Madrid.

McGEOCH, J. A. - "The Formal Criteria of a systematic psychology". Psychological Review. 1933. 40, 1-12.

MACKENZIE, B. D. - Behaviourisme and the Limits of Scientific Method. Humanities Press, Atlantic High Hands. 1977.

MEEHL. P. E. - Clinical vs. Statistical Prediction: a Theoretical Analysis and a Review of the Evidence. University of Minnesota. Minneapolis, 1954.

MERCIER, D. J.: Psicología. Nueva Biblioteca Filosófica, Madrid, 1940.

MERLEAU-PONTY, M. - Les Sciences de l'homme et la phenomenologie. Centre de Documentation Universitaire, Paris (Trad.: Nova, 1964).

MILLER, G. A.; GALANTER, E. and PRIBRAM, K. H. - Plans the Structure of Behavior. Holt, N. York, 1960.

MISIAK, H. - The Philosophical Roots of Scientific Psychology. Fordham University Press, N. York, 1961 (Trad.: Troquel, 1964).

MURCHISON, C. (ed.) - Psychologies of 1925. Clark Univ. Press, Worcester, Mass, 1926.

MURCHISON, C. (ed.) - Psychologies of 1930. Clark Univ. Press, Worcerter, Mass, 1930.

NEVILL, D. D. - Humanistic Psychology: New Frontiers. Gardner, N. York, 1977.

NEWELL, A. - "You can't play 20 questions with nature and win: Projective commets on the papers of this symposium". En: CHASE, W. G.: Visual Information Processing. Academic Press, N. York, 1973.

NUDLER, O. (ed.) - Problemas Epistemológicos de la Psicología. Siglo XXI, Buenos Aires, 1975.

ORCHARD

PALERMO, D. S. - "Is a scientific revolution taking place in, psychology". Science Studies 1971, 1, 135-55.

PIAGET, J. - "La psychologie". En PIAGET et al.: Tendances principales de la Recherche dans les Sciences Sociales et Humaines. Partie I: Science Sociales. UNESCO, París (Trad.: Alianza, 1973, pp. 121-199).

PINILLOS, J. L. - Introducción a la Psicología Contemporánea. C. S. I. C., Madrid, 1962. 
PINILLOS, J. L. - “La psicología fenomenológica". En Homenaje a Xavier Zubiri. Moneda y Crédito, Madrid, 1970.

REUCHLIN. M. - "Options fundamentales et optiones superficielles". Revue de Psychologie Appliquée, 1970, 31, 2, 97-116.

ROYCE, J. R. y MOS, L. P. - Humanistic Psychology. Concepts and Cristicisms. Plenum Press, N. york, 1981.

RYCHLAK, J. F. - The Psychology of Rigorous Humanism. Wiley-Interscience, N. York, 1977.

RYLE, G. - Concepts of Mind. Hutchinson, London, 1949. (Trad.: Paidós, 1967).

SAHAKIAN, W. - History of Psychology. A Source Book in Systematic Psychology. Peacock Pub. Itasca, 1968.

SEVERIN, F. T. - Humanistic Viewpoints in Psychology: A Book of Readings. McGraw Hill, N. York, 1966.

SPIEGELBERG, H. - Phenomenology in Psychology and Psychiatry. NorthWestem Univ. Press, Evanston, 1972.

STAATS, A. W. - Psychology's Crisis of Disunity. Philosophy and Method for a Unified Science. praeger, N. York, 1983.

STEVENS, S. S. - "The operational basis of psychology". American Journal of Psychology. $1935,47,323-30$.

STEVENS, S. S. - "Psychology and the science of science". Psychological Bulletin. 36, 1939. 221-63.

STEVENS, S. A. (ed.) - Handbook of Experimental Psychology. Wiley. N. York 1951.

STRAUS, E. - Phenomenological Psychology. Basic Books, N. York, 1966.

SUPPE, F. - The Structure of Scientific Theories. Univ. of Illinois Press, Urbana, 1977.

TAYLOR, CH. - The Explanation of Behavior. Routledge Kegan, London, 1964.

TELFORD, CH. W. and SAWREY, J. M. - Psychology as a Natural Science. Brooks/Cole Pub. Co., Monterrey, 1972.

TOULMIN, S. - Human Understanding. Princetown Univ. Press, 1972 (Trad.: Alianza Univ.. 1977).

TURNER, M. B. - Philosophy and the Science of Behavior. Appleton Century Crofts, N. York, 1967.

TYLER

VAN KAAM, A. L. - Existencial Foundations of Psychology. Image Books, Garden City, N. York, 1969.

WARREN, N. - "is a scientific revolution taking place in psychology? Doubts and reservation". Science Studies, 1971, 1, 407-13.

WATSON, R. I. - "Psychology: A perspective science". American Psychologist. 1967. 22. 435. 443.

WEIMER, W. B. and PALERMO, D. S. - Cognition and the Symbolic Process. LEA Hillsdale, 1974.

WERHEIMER, M. - Fundamental Issues in Psychology. Holt. N. York, 1972.

WESTLAND, G. - Current Crises of Psychology. Heineman, London, 1978.

WOODWORTH, R. S. - Contemporary Schools of Psychology. Ronald Press, N. York, 1931.

WYSS, D. - Die Tiefenpsychologischen Schulen von den Anfangen bis zur Gegenwart. Vandenhoeck und Ruprecht, Gottingen. 1961. (Trad.: Gredos 1964).

ZAZZO, R. - "Conciencia y conducta". En CANESTRELLI et al.: Le Comportement. P. U. F., París, 1969 (trad.: Proteo, pp. 75, 93). 